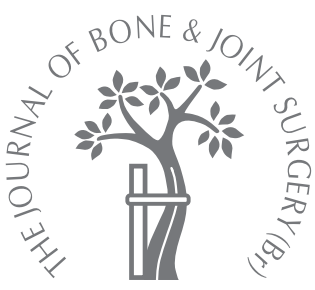

A. M. Nada, U. K. Debnath, D. A. Robinson, C. Jordan

From The Neville Hall Hospital, Abergavenny, United Kingdom

\title{
Treatment of massive rotator-cuff tears with a polyester ligament (Dacron) augmentation
}

\author{
CLINICAL OUTCOME
}

We describe the clinical outcome of a technique of surgical augmentation of chronic massive tears of the rotator cuff using a polyester ligament (Dacron) in 21 symptomatic patients (14 men, seven women) with a mean age of 66.5 years (55.0 to 85.0). All patients had MRI and arthroscopic evidence of chronic massive tears. The clinical outcome was assessed using the Constant and Murley and patient satisfaction scores at a mean follow-up of 36 months (30 to 46 ).

The polyester ligament $(500 \mathrm{~mm} \times 10 \mathrm{~mm})$ was passed into the joint via the portal of Neviaser, medial to the tear through healthy cuff. The two ends of the ligament holding the cuff were passed through tunnels made in the proximal humerus at the footprint of the insertion of the cuff. The ligament was tied with a triple knot over the humeral cortex.

All the patients remained free from pain $(p<0.001)$ with improvement in function $(p<0.001)$ and range of movement $(p<0.001)$. The mean pre-operative and post-operative Constant scores were 46.7 (39.0 to 61.0$)$ and 85.4 (52.0 to 96.0), respectively ( $<<0.001)$. The mean patient satisfaction score was $90 \%$. There were two failures, one due to a ruptured ligament after one year and the other due to deep-seated infection. The MR scan at the final follow-up confirmed intact and thickened bands in 15 of 17 patients.

This technique of augmentation gives consistent relief from pain with improved shoulder movement in patients with symptomatic massive tears of the rotator cuff.

Chronic massive tears of the rotator cuff are a surgical challenge ${ }^{1-5}$ because they are associated with atrophy and fatty infiltration of the cuff $^{6-8}$ and arthritis of the shoulder, thereby making reconstruction difficult. ${ }^{9}$ This disabling condition is associated with a poor prognosis. Conservative management, simple debridement and decompression, partial repairs, tendon transfers and reconstruction have been advocated with variable results. ${ }^{1-5,7,10-19}$ Although the outcome after attempted reconstruction remains uncertain, ${ }^{20}$ the use of a synthetic graft may provide a means of redirecting forces across the shoulder. ${ }^{15,21}$

Polyethylene terephthalate (Dacron Xiros, Leeds, United Kingdom), has a high tensile strength with linear stress-strain and can resist forces of up to $3000 \mathrm{~N}$. It has been used successfully in ligament augmentation reinforcement systems (LARS; Corin group plc, Cirencester, United Kingdom). ${ }^{22}$ It is a nonresorbable, biocompatible material with little tissue irritability and has excellent affinity for bone and tendon. These properties are similar to those of polytetrafluroethelene (Davol Inc., Warwick, United Kingdom) or Teflon which has been used for repairs of the rotator cuff. ${ }^{23}$ It is used to move the point of insertion of the tendon of supraspinatus laterally in massive tears in order to optimise the lever arm. ${ }^{24}$

We describe a technique for reconstruction of massive rotator-cuff tears using Dacron to augment the repair and present the clinical outcome.

\section{Patients and Methods}

The prospective study included 21 symptomatic patients (14 men, seven women) with a mean age of 66.5 years (55.0 to 85.0) who had MRI evidence of massive tears of the rotator cuff. The mean duration of symptoms was for 20.8 months (6.0 to 48.0$)$. The dominant limb was involved in $76 \%$ of cases (16 right, five left). Three patients had a previous repair which had failed.

The inclusion criteria were the presence of a full-thickness massive tear of the rotator cuff confirmed by MRI and intra-operative assessment, unacceptable pain and disability after failure of conservative treatment, a functional deltoid muscle, and compliance with a strict post-operative regime of rehabilitation. The exclusion criteria were cuff tear arthropathy 
with stiffness, a history of infection, and any neurological condition affecting the function of the shoulder girdle.

Massive tears were defined as those involving $\geq 5 \mathrm{~cm}$ of the diameter and at least two of the four musculotendinous units. ${ }^{25}$ All the patients had pain, but no stiffness. They had received conservative treatment for a minimum of six months including injection of steroid (40 mg of DepoMedrone and $1 \%$ lignocaine) through a posterior approach, and physiotherapy. The response to injection varied from none to temporary relief for three months, but without improvement in function. They had also undergone a progressive strengthening programme, incorporating scapular stabilisation and active assisted, isometric and proprioceptive exercises. Manual therapy to facilitate movement was incorporated if required.

Imaging studies included plain radiography and MRI. The former was also used to exclude glenohumeral osteoarthritis and the latter was also performed at the final mean follow-up of 36 months (30 to 46). All the images were taken using a 1.5T Siemens MR scanner (Siemens Medical Solutions, Malvern, Pennsylvania) with a dedicated 16-channel shoulder coil. Proton-density fat-saturated images were obtained in the axial, parasagittal and coronal oblique plains along with $\mathrm{T} 1$ coronal/oblique turbo spin echo images. The mean slice thickness was $3 \mathrm{~mm}$. All the pre- and post-operative MR scans were graded according to the system of Goutallier et al ${ }^{8}$ as follows: grade 0 , normal; grade 1 , muscle contains some fatty streaks; grade 2, fatty infiltration, but more muscle than fat; grade 3, fatty infiltration equal to muscle fibres; and grade 4 , more fatty infiltration than muscle fibres.

The patients were informed that they would undergo a standard arthroscopic repair but if the edge of the rotator cuff could not be mobilised to its insertion then a mini-open Dacron ligament augmentation procedure would be performed. The study had ethical approval and the patients gave informed consent.

Operative technique. A band of polyester fibre mesh (Dacron) ligament (Xirox plc, Leeds, United Kingdom) $500 \mathrm{~mm}$ long and $10 \mathrm{~mm}$ wide was used for the augmentation (Fig. 1).

All the procedures were performed by the senior author $(\mathrm{AMN})$ in the beach-chair position under general anaesthesia and/or interscalene block and with an intravenous injection of $750 \mathrm{mg}$ of Cefuroxime. Arthroscopy was undertaken using standard posterior and lateral portals and the edge of the torn cuff identified. The subacromial space was decompressed. An attempt to bring the cuff to its insertion failed in all patients.

The incision at the lateral portal was extended superiorly from the tip of the acromion by approximately $5 \mathrm{~cm}$. A deltoid split was carried out and the cuff was mobilised by blunt dissection. Curved artery forceps were introduced through healthy cuff tissues via the Neviaser portal in the notch between the posterior acromio-clavicular joint and the spine of the scapula. The Dacron ligament was grasped and withdrawn through this portal (Fig. 2a). A hook was introduced over the upper surface of the cuff and the upper

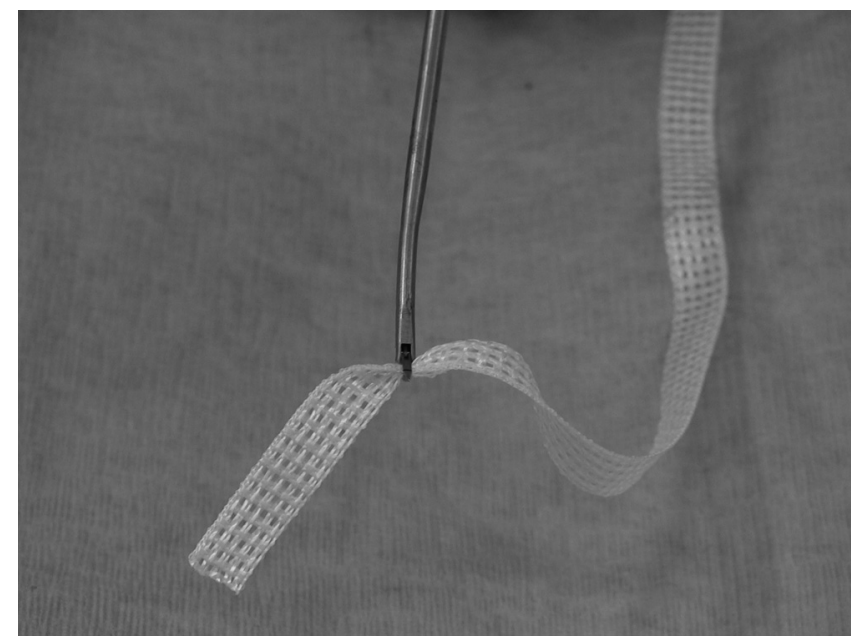

Fig. 1

Photograph of the Dacron ligament $(500 \mathrm{~mm} \times 10 \mathrm{~mm})$.

aspect of the ligament was delivered through the lateral wound (Fig. 2b). Depending on the extent of the tear, the same procedure was repeated either through the Neviaser or anterosuperior portals to deliver the lower aspect of the ligament through the cuff from its inferior to superior surface (Figs $2 \mathrm{c}$ and $2 \mathrm{~d}$ ). The configuration should be such that both aspects of the ligament are situated at the middle of the torn cuff. The footprint of the insertion of the cuff was identified and two tunnels made with a $2.5 \mathrm{~mm}$ drill. Having tensioned the ligament, its two ends holding the cuff were passed through the tunnels using a snare. Keeping the arm in $20^{\circ}$ to $30^{\circ}$ of abduction, the ligament was tied securely over the humeral cortex (Fig. 2d). The remnant of the cuff was sutured to the flattened ligament to close the defect as much as possible and the resultant augmentation thereby bridged the gap between the edge of the cuff and its insertion. This prevented buttonholing of the humeral head and maximised the function of the deltoid muscle.

A polysling was used for five days and then intermittently for a maximum of two weeks. Active hand, wrist and elbow movements were instituted from the first day. Gentle active and passive shoulder mobilisation, including pendulum exercises, were started after five days and continued for the first six weeks. Scapular stabilisation exercises were begun after six weeks with gradual progression to resisted exercises. All mobilisation and exercises were performed within the pain-free range of movement (ROM).

Functional evaluation. The patients were evaluated preoperatively by an experienced physiotherapist (CJ). Supraspinatus was weak in all cases. Pain, activities of daily living and movement, strength and function were assessed using the Constant-Murley score. ${ }^{26}$ Pain was assessed using a visual analogue scale (VAS) ranging from 0 (no pain) to 10 (severe). The active ROM of flexion and external rotation were assessed in multiple positions. Strength was tested manually and graded using a standard MRC five- 

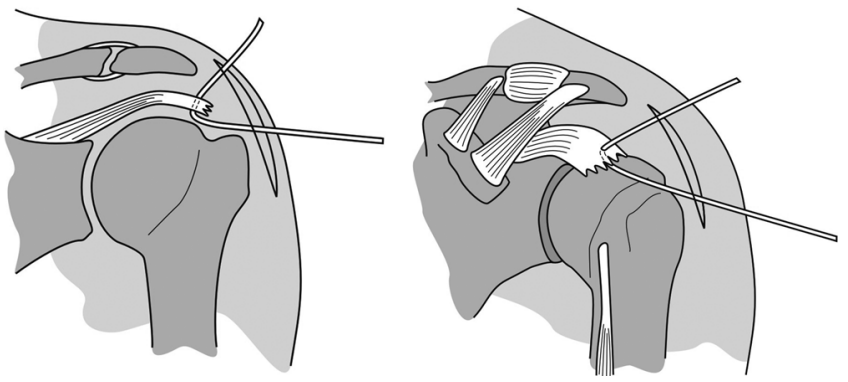

Fig. 2a

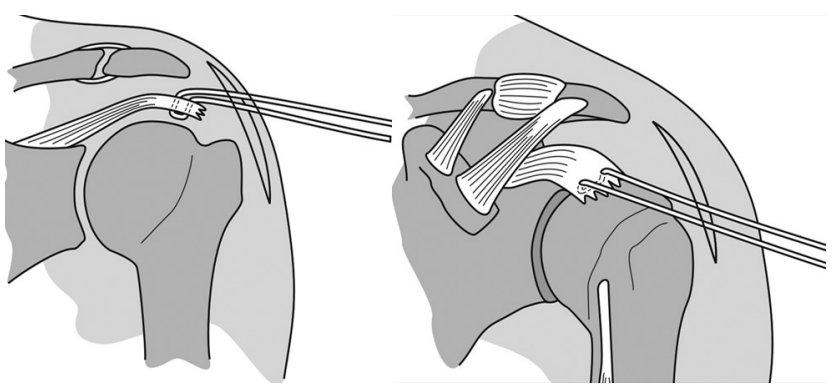

Fig. 2c
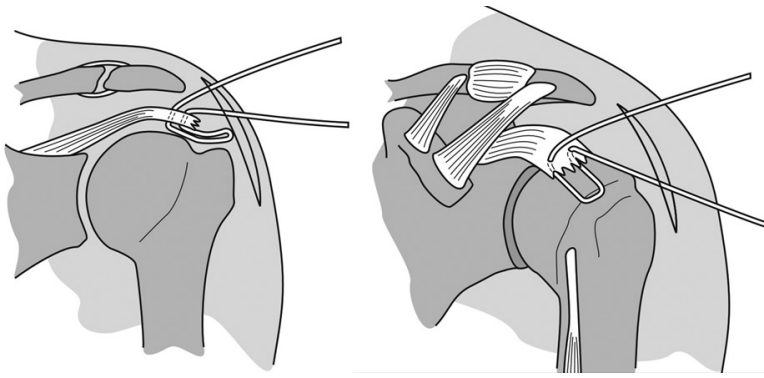

Fig. 2b
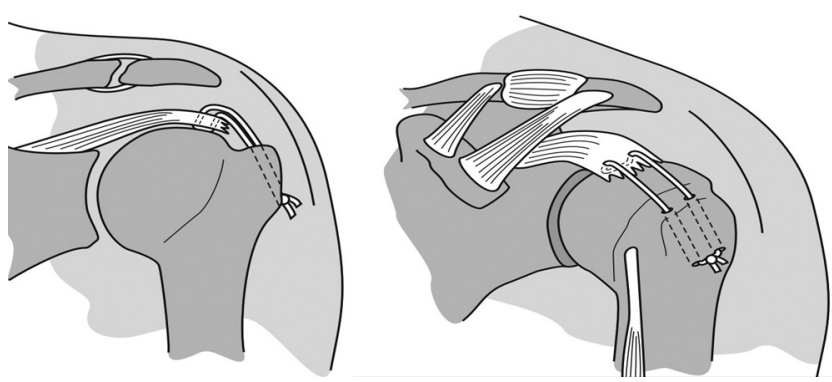

Fig. 2d

Diagram showing a) the Dacron ligament passed through the retracted rotator cuff via a supraspinatus portal (Nevaiser) using curved artery forceps, b) the upper aspect of the ligament is passed through the inferior and then superior surface of the rotator cuff using a hook through the lateral incision (not the same portal as in a), c) mobilisation of supraspinatus by constant tension on the ligament and the creation of two tunnels at footprint on the greater tuberosity and d) the ligament passed through the two bony tunnels while maintaining the tension on the rotator cuff. The two ends of the ligament are tied with a triple knot maintaining the tension in the rotator cuff.

point scale for muscle strength. The same physiotherapist supervised the rehabilitation programme.

The patients were seen at six, 12, 24 and 36 months postoperatively and the same outcome measures were used. The Constant scores were also calculated without the strength component. At the final follow-up, all the patients were scored subjectively for satisfaction on a four-point Likert scale $^{27}$ ranging from very satisfied, satisfied, somewhat satisfied to dissatisfied. Their work status was recorded.

Radiological assessment. A consultant musculoskeletal radiologist (DAR) was familiarised with the operative technique and independently assessed the MR scans. The scans of 17 patients were evaluated at the final follow-up to determine the integrity of the augmented cuff and the amount of fatty infiltration of the cuff muscles.

Two patients with multiple metal anchors in the humeral tuberosity were excluded because a severe artefact signal obscured the repair. In the other 15 scans, the augmented cuff had a low/intermediate signal on the proton density fat-saturated images, becoming almost black in most repairs, presumably because of progressive infiltration of collagen across the Dacron mesh. The fatty infiltration was visualised on the T2-weighted images.

Statistical analysis. The data were tested for normality before statistical analysis which was performed using
Student's $t$-test (SPSS version 15; SPSS Inc., Chicago, Illinois). A p-value $\leq 0.05$ was considered to be significant.

\section{Results}

Pre-operatively, 16 patients $(76.2 \%)$ had night pain and $19(90.5 \%)$ described their pain as intolerable with a VAS > 7.0. No patient had stiffness.

All but one had considerable relief from pain. The mean pain score improved from 7.0 pre-operatively to 1.0 postoperatively (Table I). Only two patients had occasional pain with overuse which was relieved by analgesics. There was also significant improvement in the mean scores for the activities of daily living, from 8.6 pre-operatively to 16.9 post-operatively $(t$-test, $\mathrm{p}<0.001$, Table I).

The mean active flexion improved from $65^{\circ}\left(55^{\circ}\right.$ to $\left.85^{\circ}\right)$ pre-operatively to $120^{\circ}\left(90^{\circ}\right.$ to $\left.160^{\circ}\right)$ post-operatively (Table I). The mean active abduction improved from $60^{\circ}$ $\left(50^{\circ}\right.$ to $\left.70^{\circ}\right)$ pre-operatively to $120^{\circ}\left(90^{\circ}\right.$ to $\left.140^{\circ}\right)$ postoperatively and 18 patients could elevate forward beyond $105^{\circ}$. The mean external and internal rotation of the operated shoulder improved significantly (Table I).

The strength of abduction improved by at least one grade in all patients, allowing them to perform regular activities, with a few returning to leisure pursuits such as fishing and golf. A 60-year-old woman was able to return to playing 
Table I. Pre- and post-operative mean Constant and Murley ${ }^{26}$ scores

\begin{tabular}{|c|c|c|c|c|}
\hline Score & Pre-operative & Post-operative & Mean difference & p-value \\
\hline Total score (out of 100) & 46.7 (39 to 61 ) & 84.5 (52 to 96$)$ & 37.8 & $<0.001$ \\
\hline Score without strength (out of 75) & 28.3 (21 to 35 ) & 61.4 (32 to 71$)$ & 33.1 & $<0.001$ \\
\hline Pain & $7.0(5.0$ to 8.0$)$ & $1.0(0.0$ to 2.0$)$ & 6 & $<0.001$ \\
\hline Activities of daily living & 8.6 (7 to 11$)$ & 16.9 (15 to 20$)$ & 8.3 & $<0.001$ \\
\hline \multicolumn{5}{|l|}{ Active movement $\left({ }^{\circ}\right)$} \\
\hline Flexion & 65 (55 to 85 ) & 120 (90 to 160$)$ & 55 & $<0.001$ \\
\hline Abduction & 60 (50 to 70$)$ & 120 (90 to 140$)$ & 60 & $<0.001$ \\
\hline External rotation & 39 (30 to 50$)$ & $57(30$ to 70$)$ & 18 & $=0.01$ \\
\hline Internal rotation (score) & 4.2 (4 to 6$)$ & $8.4(6$ to 10$)$ & 4.2 & $=0.008$ \\
\hline Abduction strength (score) & 3.9 (3 to 5$)$ & 5.0 & 1.1 & $=0.03$ \\
\hline
\end{tabular}
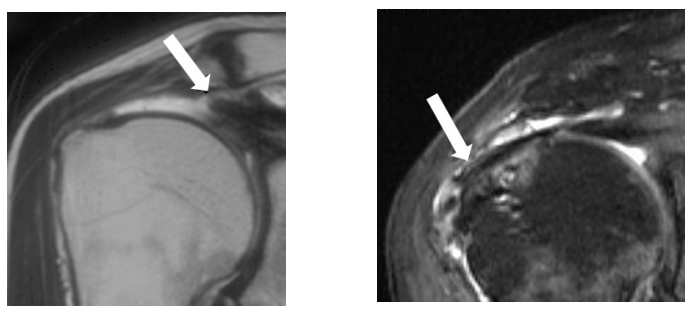

Fig. 3a

Fig. 3b

MR scans of the right shoulder of a 62-year-old woman showing a) pre-operatively (T2-weighted) the chronic massive tear and b) post-operatively at three years (proton density fat-saturated) the intact ligament reconstruction.

the violin professionally within four months of the operation. In 19 patients the mean overall Constant score improved significantly from 46.7 pre-operatively to 84.5 at the final follow-up. The overall results were excellent in 17 patients, good in two, fair in one and poor in one. The Constant scores were recalculated without the strength component (Table I). This made no difference to the final outcome. Subjectively, $19(90 \%)$ were satisfied with the result and satisfaction correlated significantly with the post-operative Constant score (Spearman's correlation coefficient, $\mathrm{p}=0.001)$. A better functional outcome was associated with a higher degree of satisfaction in all 19 patients. The two patients with metal anchors had high Constant scores and were satisfied with the outcome.

One patient with a previously failed repair did well for one year after the augmentation. He then returned with further symptoms. At arthroscopy, the Dacron ligament was torn. He underwent a further augmentation of the remaining rotator-cuff tissue with Dacron ligament. At two years follow-up, his pain had eased, but his ROM had not improved. This outcome was rated as fair.

A 55-year-old right-handed woman had deep-seated infection at the end of the first post-operative week. Arthroscopic wound irrigation and debridement did not
Table II. Grading of fatty degeneration on the preoperative MR scan according to Goutallier et $\mathrm{al}^{8}$

\begin{tabular}{lllll}
\hline & \multicolumn{4}{l}{ Goutallier grade } \\
\cline { 2 - 5 } Rotator cuff & $\mathbf{1}$ & $\mathbf{2}$ & $\mathbf{3}$ & $\mathbf{4}$ \\
\hline Supraspinatus & 0 & 9 & 5 & 1 \\
Infraspinatus & 0 & 8 & 6 & 1 \\
Subscapularis & 7 & 4 & 3 & 1 \\
\hline
\end{tabular}

clear the infection and the ligament was removed, which allowed her wound to heal. No further reconstruction was undertaken and her result was poor.

Radiological findings. MRI was used to visualise the two bands of the augmented cuff and the persistent central defect between the bands. This was not misinterpreted as a failure of the reconstruction. In four patients the edge of the cuff was at the same site as in the pre-operative MR scan but in 11 it was at the crest of the curve of the humeral head (Fig. 3).

The pre-operative fatty degeneration of supraspinatus was grade 2 in nine patients, grade 3 in five and grade 4 in one (Table II). In the grade 2 group five patients remained unchanged post-operatively, three improved and one deteriorated. In the grade 3 group, four were unchanged and one improved and in the grade 4 group one improved. Therefore, the overall improvement in supraspinatus was by one grade in five patients.

The pre-operative fatty degeneration of infraspinatus was grade 2 in eight patients, grade 3 in six and grade 4 in one (Table II). In the grade 2 group four were unchanged post-operatively, one improved and three deteriorated. In the grade 3 group six remained unchanged and in the grade 4 group one remained unchanged. Therefore, most infraspinati (11 of 15, 73\%) remained unchanged and three deteriorated. The degeneration in subscapularis was unchanged in 14 of 15 patients; in one it improved from grade 3 by one grade.

Clinicoradiological correlation. Most patients (8 of 9) with grade 2 fatty degeneration of supraspinatus had an excellent functional outcome. Although one showed 
deterioration, it did not affect the final outcome. Although there was radiological improvement in the degeneration in the grade 3 group in only one patient, all five in this group had a clinically significant improvement in function $(\mathrm{p}<$ $0.001)$. The only patient in the grade 4 group who had radiological improvement also had a higher Constant score at the final follow-up. The radiological fatty degenerative changes in infraspinatus and subscapularis did not seem to influence the final clinical outcome.

\section{Discussion}

The natural history of massive tears of the rotator cuff is not known. A considerable proportion defy traditional techniques of repair or reconstruction and a number of operative techniques have been described for these irreparable tears with variable success. ${ }^{1,4-7}$ The results of repair have been reported to be good in many series with relief from pain in $90 \%$ of patients and restoration of function. ${ }^{1,10-12}$ The size of the tear has not been shown to be an indicator of patient satisfaction. ${ }^{28}$

Autogenous grafts for reconstructing the tears have had a high rate of failure in both primary and revision operations. ${ }^{4}$ Autogenous tissues, such as fascia lata or other tendons, tend to wear and stretch. Carbon fibre, ${ }^{29}$ patch grafting ${ }^{11}$ and xenografts ${ }^{30}$ have also been used unsuccessfully.

Ozaki et a $\mathrm{l}^{15}$ presented the first series of patients treated with synthetic polyester grafts for massive tears. At the end of two years, 23 of 25 patients were pain free and had improved abduction of $120^{\circ}$ to $160^{\circ}$. Two patients had an injury to the axillary nerve with poor results. No standardised scoring system was applied to evaluate their results. Ozaki et al ${ }^{15}$ suggested that Teflon felt and Marlex possess high tensile strength and low friction, and may be as thick as the rotator cuff when implanted. Kimura et $\mathrm{al}^{23}$ also reported good results in 30 patients who had received Teflon felt grafts and in an experimental study involving the reconstruction of infraspinatus in dogs, they showed that these grafts improved their tensile strength over three months post-operatively. ${ }^{23}$

The successful outcome after reconstruction with a Dacron ligament in our series suggests that these grafts can withstand loads during elevation and abduction. It is also known that collagen in bone and tendon bonds with synthetic polyester fibres. ${ }^{23}$ The ligament has fibres $1 \mathrm{~cm}$ wide and a closed mesh to allow for collagen ingrowth, thereby increasing the stiffness and bonding.

Mura et $\mathrm{al}^{21}$ suggested that a synthetic graft can provide a way of redirecting force to the glenohumeral joint and Burkhart ${ }^{31}$ described the biomechanical rationale for repair of massive tears of the rotator cuff. He suggested that as long as the tear does not extend below the equator of the humeral head, the remainder of the cuff can maintain the head in the glenoid without superior translation and guide the shoulder in forward elevation by coupling with the deltoid. Therefore, intact deltoid function is a prerequisite for reconstruction or repair of the rotator cuff.
In our technique every effort was made to bring the cuff over the crest of the humeral head before tying the knot in tension. The two bands of the Dacron ligament prevented the head from buttonholing superiorly and allowed the shoulder to regain function.

The final follow-up MR scans suggested that 15 patients $(88 \%)$ had the edge of the augmented cuff at the crest of the humeral head. Many clinical studies of open and arthroscopic techniques of repair of the rotator cuff have emphasised the importance of stable fulcrum kinematics and force coupling around the shoulder as important factors predicting outcome. ${ }^{32-34}$ The closure of the rent in the rotator cuff is not essential for re-establishing stable kinematics. ${ }^{35}$ The favourable outcome in our series strengthens this concept.

The correlation between the clinical and MRI assessment confirmed that grade 3 and grade 4 fatty infiltration of supraspinatus did not influence the outcome after augmentation. Deterioration in infraspinatus progressed in a few patients without affecting the outcome. These results substantiated those of Goutallier et al. ${ }^{8}$ Although it is difficult to draw conclusions from the small number of patients, the MRI findings suggested that augmented repair prevented further deterioration of supraspinatus and subscapularis.

The failure of the repair of massive tears using suture techniques was studied prospectively by Boehm et $\mathrm{al}^{36}$ who suggested that the weakness was at the tendon-suture interface, the thread and the suture-to-bone interface. In confirmed re-tears of the reconstructed rotator cuff, the use of non-absorbable sutures gave a poorer outcome than that with absorbable sutures, with lower Constant scores in the failed group ( $77 \%$ vs $94 \%$ ).

Zumstein et $\mathrm{al}^{37}$ used a transosseous technique of repair in all patients and found a re-rupture rate of $37 \%$ at three years and of $57 \%$ at follow-up at nine years. Our method of reconstruction was made easier by drilling two holes at the footprint of the rotator cuff which gave good anchorage for the knot on the outer side of the bone. The mean post-operative Constant score was 84.5 which was similar to that of Gerber et al. ${ }^{4}$ Rokito et $\mathrm{al}^{38}$ found that at least one year was needed before the strength of the shoulder was restored after repair of large tears. In our series, improvement in abduction strength was observed in $90 \%$ of patients at one year but improved very little thereafter.

Re-rupture after repair of tears of the rotator cuff is due to the weak link of the reconstructed muscle-tendon-bone unit and failed osteofibroblastic integration. ${ }^{17,39}$ Reduced strength after failed repairs has been reported. ${ }^{34}$ Scheibel et $\mathrm{al}^{17}$ described the functional outcome after reconstruction of the rotator cuff using an autologous periosteal flap and demonstrated a re-rupture rate of $20 \%$ as seen on follow-up MR scans. Hanusch et $\mathrm{al}^{18}$ noted that four of 24 patients $(17 \%)$ had a re-tear as diagnosed by ultrasonograph. In our series, only one patient had a torn Dacron ligament and the follow-up MRI findings strengthened the concept of using Dacron mesh for aug- 
menting the repair of chronic massive tears with subjective satisfaction scores of excellent or good in $90 \%$ of patients.

The strengths of our study include the description of a new technique, prospective collection of data, the availability of pre- and post-operative scores, involvement of an independent assessor and a final follow-up MR scan to assess the integrity of the repaired rotator cuff. There were some limitations. This was a single-centre study and all the operations were performed by the senior author. There was no control group and the number of patients was relatively small.

However, our findings indicate that polyester (Dacron) ligament augmentation can result in a pain free successful return of function in active symptomatic patients with massive chronic tears of the rotator cuff.

\section{Listen live}

Listen to the abstract of this article at www.jbjs.org.uk

The author or one or more of the authors have received or will receive benefits for personal or professional use from a commercial party related directly or indirectly to the subject of this article.

\section{References}

1. Bigliani LU, Cordasco FA, McLiveen SJ, Musso ES. Operative treatment of failed repairs of the rotator cuff. J Bone Joint Surg [Am] 1992;74-A:1505-15

2. Ellman H, Hanker G, Bayer M. Repair of the rotator cuff: end result study of factors influencing reconstruction. J Bone Joint Surg [Am] 1986;68-A:1136-44.

3. Hawkins RJ, Misamore GW, Hobeika PE. Surgery for full thickness rotator cuff tears. J Bone Joint Surg [Am] 1985;67-A:39-55.

4. Gerber C, Fuchs B, Holder J. The results of repair of massive tears of the rotato cuff. J Bone Joint Surg [Am] 2000;82-A:505-15.

5. Gartsman GM. Massive, irreparable tears of the rotator cuff: results of operative debridement and subacromial decompression. J Bone Joint Surg [Am]1997;79-A:71521.

6. Nakagaki K, Ozaki J, Tomita Y, Tamais S. Alterations in the supraspinatus muscle belly with rotator cuff tearing: evaluation with magnetic resonance imaging. J Shoulder Elbow Surg 1994;3:88-93.

7. Mellado JM, Clamet J, Olona M, et al. Surgically repaired massive rotator cuff tears: MRI of tendon integrity, muscle fatty degeneration and muscle atrophy correlated with intraoperative and clinical findings. AJR Am J Roentgeno/ 2005;184:1456-63.

8. Goutallier D, Postel JM, Bernageau J, Lavau L, Voisin MC. Fatty muscle degeneration in cuff ruptures: pre and post-operative evaluation by CT scan. Clin Orthop 1994;304:78-83

9. Sugihara T, Nakagawa T, Tsuchiya M, Ishizuki M. Prediction of primary reparability of massive tears of the rotator cuff on preoperative magnetic resonance imaging. J Shoulder Elbow Surg 2003;12:222-5.

10. Dualde XA, Bair B. Massive rotator cuff tears: the result of partial rotator cuff repair. J Shoulder Elbow Surg 2005;14:121-7.

11. Audenaert E, VanNuffel J, Schepens A, Verhelst M, Verdonk R. Reconstruction of massive rotator cuff lesions with a synthetic interposition graft: a prospective study of 41 patients. Knee Surg Sports Traumatol Arthrosc 2006;14:360-4

12. Warner JJ. Management of massive irreparable rotator cuff tears: the role of tendon transfer. Instr Course Lect 2001;50:63-71

13. Iannotti JP, Hennigan S, Herzog R, et al. Latissimus dorsi tendon transfer for irreparable posterosuperior rotator cuff tears: factors affecting outcome. J Bone Joint Surg [Am] 2006;88-A:342-8.
14. Neviaser JS, Neviaser RJ, Neviaser TJ. The repair of chronic massive ruptures of the rotator of the shoulder by use of a freeze-dried rotator cuff. J Bone Joint Surg [Am] 1978:60-A:681-4.

15. Ozaki J, Fujimoto S, Masuhara K, Tamai S, Yoshimoto S. Reconstruction of chronic massive rotator cuff tears with synthetic materials. Clin Orthop 1986;202:173-83.

16. Baysal D, Balyk R, Otto D, Luciak-Corea C, Beaupre L. Functional outcome and health-related quality of life after surgical repair of full-thickness rotator cuff tear using a mini-open technique. Am J Sports Med 2005;33:1346-55.

17. Scheibel M, Brown A, Woertler K, Imhoff AB. Preliminary results after rotator cuff reconstruction augmented with an autologous periosteal flap. Knee Surg Sports Traumatol Arthrosc 2007:15:305-14

18. Hanusch BC, Goodchild L, Finn P, Rangan A. Large and massive tears of the rotator cuff: functional outcome and integrity of the repair after a mini-open procedure. $J$ Bone Joint Surg [Br] 2009;91-B:201-5.

19. Habermeyer $\mathbf{P}$, Magosch $\mathbf{P}$, Rudolph $\mathbf{T}$, Lichtenberg $\mathbf{S}$, Liem D. Transfer of the tendon of latissimus dorsi for the treatment of massive tears of the rotator cuff, a new single-incision technique. J Bone Joint Surg [Br] 2006;88-B:208-12.

20. DeOrio JK, Cofield RH. Results of second attempt at surgical repair of a failed initial rotator cuff repair. J Bone Joint Surg [Am] 1984;66-A:563-7.

21. Mura N, O'Driscoll SW, Zobitz ME, Heers G, An KN. Biomechabnical effect of patch graft for large rotator cuff tears: a cadaver study. Clin Orthop 2003;415:131-8.

22. Dominkus M, Sabeti M, Toma C, et al. Reconstructing the extensor apparatus with a new polyester ligament. Clin Orthop 2006;453:328-34.

23. Kimura A, Aoki M, Fukushima S, Ishii S, Yamakoshi K. Reconstruction of a defect of the rotator cuff with polytetrafluroethylene felt graft: recovery of tensile strength and histocompatability in an animal model. J Bone Joint Surg [Br] 2003:85B:282-7

24. Skrbensky GV, Lass R, Huber R. The biomechanical testing of the insertion point after supraspinatus reconstruction. Procs 60th Annual Meeting Canadian Orthopaedic Association, Montreal, 2005

25. Cofield RH. Rotator cuff disease of the shoulder. J Bone Joint Surg [Am] 1985;67A:974-9.

26. Constant CR, Murley AH. A clinical method of functional assessment of the shoulder. Clin Orthop 1987;214:160-4.

27. Likert R. A technique for the measurement of attitudes. Archives of Psychology 1932;140:1-55

28. Sonnabend DH, Watson EM. Structural factors affectng the outcome of rotator cuff repair. J Shoulder Elbow Surg 2002;11:212-18.

29. Visuri T, Kiviluoto 0, Eskelin M. Carbon fibre for repair of the rotator cuff: a 4 year follow-up of 14 cases. Acta Orthop Scand 1991;62:356-9

30. Walton JR, Bowman NK, Khatib Y, Linklater J, Murrell GAC. Restore orthobio logic implant: not recommended for augmentation of rotator cuff tears. J Bone Joint Surg [Am] 2007;89-A:786-91

31. Burkhart SS. Arthroscopic treatment of massive rotator cuff tears: clinical results and biomechanical rationale. Clin Orthop 1991;267:45-56.

32. Iannotti JP. Full thickness rotator cuff tears: factors affecting surgical outcome. J Am Acad Orthop Surg 1994;2:87-95.

33. Harryman DT 2nd, Mack IA, Wang KY, et al. Repairs of the rotator cuff: correlation of functional results with integrity of the cuff. J Bone Joint Surg [Am] 1991;73A:982-9.

34. Jost B, Pfirrmann C, Gerber C, Switzerland Z. Clinical outcome after structura failure of rotator cuff repairs. J Bone Joint Surg [Am] 2000;82-A:304-14.

35. Burkhart S, Nottage WM, Ogilvie-Harris DJ, Kohn HS, Pachelli A. Partia repair of irreparable rotator cuff tears. Arthroscopy 1994;10:363-70.

36. Boehm TD, Werner A, Radtke S, et al. The effect of suture materials and tech niques on the outcome of repair of the rotator cuff: a prospective randomized study. J Bone Joint Surg [Br] 2005;87-B:819-23.

37. Zumstein MA, Jost B, Hempel J, Hodler J, Gerber C. The clinical and structura long term results of open repair of massive tears of the rotator cuff. J Bone Joint Surg [Am]2008;90-A:2423-31.

38. Rokito AS, Cuomo F, Gallagher MA, Zuckerman JD. Long-term functional outcome of repair of large and massive chronic tears of the rotator cuff. J Bone Joint Surg [Am] 1999;81-A:991-7.

39. Cummins CA, Murrell GAC. Mode of failure for rotator cuff repair with suture anchors identified at revision surgery. J Shoulder Elbow Surg 2003;12:128-33. 